\title{
The effect of primary granulocyte-colony stimulating factor prophylaxis on the incidence of febrile neutropenia in patients with testicular germ cell tumors
}

\author{
Nikola Hapakova \\ Univerzita Komenskeho Lekarska fakulta \\ Michal Chovanec \\ Univerzita Komenskeho Lekarska fakulta \\ Katarina Rejlekova \\ Univerzita Komenskeho Lekarska fakulta \\ Katarina Kalavska \\ Univerzita Komenskeho Lekarska fakulta \\ Jana Obertova \\ Univerzita Komenskeho Lekarska fakulta \\ Patrik Palacka \\ Univerzita Komenskeho Lekarska fakulta \\ Valentina De Angelis \\ Univerzita Komenskeho Lekarska fakulta \\ Daniela Světlovská \\ Univerzita Komenskeho Lekarska fakulta

\section{Zuzana Sycova-Mila} \\ Narodny onkologicky ustav \\ Jozef Mardiak \\ Univerzita Komenskeho Lekarska fakulta \\ Michal Mego ( $\sim$ misomego@gmail.com ) \\ Comenius University, Faculty of Medicine
}

\section{Research article}

Keywords: Testicular germ cell tumors, febrile neutropenia, neutropenic fever, granulocyte-colony stimulating factor, prophylaxis

Posted Date: July 24th, 2020 
DOI: https://doi.org/10.21203/rs.3.rs-46060/v1

License: (c) (1) This work is licensed under a Creative Commons Attribution 4.0 International License. Read Full License

Version of Record: A version of this preprint was published at Journal of Clinical Oncology on May 20th, 2020. See the published version at https://doi.org/10.1200/JC0.2020.38.15_suppl.e17056. 


\section{Abstract}

Background: Testicular germ cell tumors (GCTs) are the most common solid malignancy in men 15-35 years old. Febrile neutropenia (FN) is a grievous complication of chemotherapy, frequently occurring in GCT patients. The aim of this retrospective study was to assess the effect of primary granulocyte-colony stimulating factor (G-CSF) prophylaxis on the incidence of FN in GCT patients.

Patients and methods: This study was conducted from medical records database of GCTs patients treated with first line/adjuvant chemotherapy from January 2000 to December 2017. Starting in January 2006, patients received G-CSF prophylaxis after every cycle of chemotherapy.

Results: Out of 393 patients, 265 patients received primary G-CSF prophylaxis and 128 patients did not receive prophylaxis. During the study period, 71 patients (18.1\%) suffered FN events. Out of 128 patients who did not receive primary prophylaxis, 42 patients suffered FN, while only 29 patients with primary prophylaxis suffered $\mathrm{FN}(32.8 \%$ vs $10.9 \%, P=0.0000001)$. On subgroup analysis, FN incidence decreased in all groups with primary prophylaxis, except for patients with stage I GCT receiving adjuvant chemotherapy. Patients receiving G-CSF prophylaxis had significantly longer overall survival when compared to patients without prophylaxis. $(\mathrm{HR}=0.44,95 \% \mathrm{Cl} 0.26-0.75 ; P=0.0009)$.

Conclusions: Primary G-CSF prophylaxis was associated with significantly decreased FN incidence in patients treated with first line chemotherapy for metastatic disease. Patients receiving G-CSF prophylaxis had significantly longer overall survival. We suggest, that primary G-CSF prophylaxis should be considered in GCT patients receiving first line chemotherapy.

\section{Introduction}

Testicular germ cell tumors (GCTs) represent only one percent of all solid tumors; however, they are the most common solid malignant tumors in men 15-35 years old.[1,2] As a result of high sensitivity of these tumors to cisplatin-based chemotherapy, GCTs have become a model for a potentially curable malignancy.[3] However, chemotherapy regimens may induce non-negligible adverse effects. Focus on prevention and appropriate management of treatment-related side effects is crucial in order to minimize morbidity, mortality and improve patients' quality of life.[4-6]

Febrile neutropenia (FN) is a life-threatening complication of cisplatin-based chemotherapy.[7, 8] Incidence of FN in GCT patients measured in previous studies varies widely.[9-12] The overall risk of developing $\mathrm{FN}$ depends on various factors that are related to the patient and to the treatment regimen. Several studies focused on identification of potential risk factors of FN in GCT patients. $[9,12,13]$ Older age has been identified as a significant risk factor for the development of FN, Feldman et al found $44 \%$ incidence of $\mathrm{FN}$ in patients older than 50 years. [13] Other strong risk factors observed by Terbuch et al were poor performance status $(\mathrm{OR}=2.73,1.47-5.06, P=0.001)$ and poor risk class according to the International Germ Cell Cancer Collaboration Group (IGCCCG) classification (OR = 4.20, $1.71-10.33, P=$ 0.002).[12] 
Prophylactic granulocyte-colony stimulating factor (G-CSF) use after treatment with myelosuppressive chemotherapy has been shown to decrease the incidence of FN in various cancers.[14] Fossa et al observed that prophylactic use of filgrastim in poor risk GCT patients is associated with decreased incidence of FN events.[15] However, study evaluating the effect of G-CSF prophylaxis on FN incidence in other GCT patients is lacking.

The aim of this retrospective study was to assess the effect of primary G-CSF prophylaxis on the incidence of $\mathrm{FN}$ and outcome in chemotherapy-naïve GCT patients.

\section{Patients And Methods}

\section{Study patients}

This retrospective study was conducted using the National Cancer Institute $(\mathrm{NCl})$ medical records database of hospitalized patients with GCTs. The study was approved by the Institutional Review Board and waiver of consent form was granted. Patients diagnosed with GCTs treated with first line/adjuvant chemotherapy at the $\mathrm{NCl}$, Bratislava, Slovakia from January 2000 to December 2017 were eligible. Patients with any concurrent malignancy, other than non-melanoma skin cancer in the previous 5 years were excluded from the study. Excluded were also patients with previous chemotherapy.

\section{Definition of FN event}

According to European society of medical oncology clinical practice guidelines, febrile neutropenia is defined as single oral temperature reading of $>38.5^{\circ} \mathrm{C}$ or two consecutive readings of $>38.0^{\circ} \mathrm{C}$ for two hours and an absolute neutrophil count of $<0.5^{\prime} 10^{9} / \mathrm{I}$ or expected to fall below $0.5^{\prime} 10^{9} / \mathrm{I}$.[16]

All episodes of febrile neutropenia occurring during first-line chemotherapy were recorded. However, only the first episodes of FN occurring in patients was classified as events.

\section{Baseline data}

During the initial staging, patients had a CT scan of the chest, abdomen and pelvis. Baseline data regarding age, primary tumor location, tumor histology, TNM stage, IGCCCG risk class and first-line chemotherapy regimen were recorded.

\section{FN prophylaxis}

None of the treated before January 2006 received primary G-CSF prophylaxis. Starting in January 2006, we progressively implemented a practice, where G-CSF prophylaxis (filgrastim or pegfilgrastim) was administered to patients after every cycle of chemotherapy. These data are summarized in Flow diagram.

\section{Statistical analysis}


We performed a retrospective review of patients' medical records. All first episodes of febrile neutropenia were classified as events. Patients' characteristics were tabulated and summarized as the median (range) values for continuous variables and frequency (percentage) for categorical variables, respectively. Fisher's exact test was used for statistical analysis to compare FN events between groups with and without prophylaxis.

Primary outcome was the overall incidence of FN events occurring during first-line chemotherapy. Secondary outcomes were incidences of FN events in various subgroups and overall survival (OS).

Median follow-up was calculated as median time of observation of study patients. OS was calculated from the start date of chemotherapy to date of the last follow-up or death of the patient. Kaplan-Meier method was used to estimate OS. The log-rank test was used to compare differences in survival between patients with and without prophylaxis. All calculations were done in NCSS 2019 statistical software.[17]

\section{Results}

\section{Patients' characteristics}

Our cohort included 393 chemotherapy naive patients with GCTs treated with first line chemotherapy (Flow diagram). Patients' characteristics are summarized in Table 1. Median age of patients at time of enrollment was 31 years (ranging from 17 to 63 years). The majority of patients (68.2\%) had nonseminomatous germ cell tumor (NSGCT). All patients received platinum-based chemotherapy. There were $128(32.6 \%)$ without primary G-CSF prophylaxis and 265 patients $(67.4 \%)$ who received primary prophylaxis. Forty patients (10.2\%) received filgrastim and $225(57.2 \%)$ patients received pegfilgrastim.

\section{Table 1 Patients' characteristics}




\begin{tabular}{|c|c|c|}
\hline & $N$ & $\%$ \\
\hline All & 393 & 100.0 \\
\hline \multicolumn{3}{|l|}{ Histology } \\
\hline seminoma & 87 & 22.1 \\
\hline NSGCT & 299 & 76.1 \\
\hline unknown & 7 & 1.8 \\
\hline \multicolumn{3}{|l|}{ Primary tumor } \\
\hline Gonadal & 351 & 89.3 \\
\hline Extragonadal & 42 & 10.7 \\
\hline Retroperitoneum & 26 & 6.6 \\
\hline Mediastinum & 12 & 3.1 \\
\hline CNS & 2 & 0.5 \\
\hline Unknown & 2 & 0.5 \\
\hline \multicolumn{3}{|l|}{ Stage } \\
\hline I.A-B & 39 & 9.9 \\
\hline I.S & 22 & 5.6 \\
\hline II.A & 31 & 7.9 \\
\hline II.B & 48 & 12.2 \\
\hline II.C & 47 & 12.0 \\
\hline III.A & 49 & 12.5 \\
\hline III.B & 50 & 12.7 \\
\hline III.C & 107 & 27.2 \\
\hline \multicolumn{3}{|l|}{ IGCCCG Risk Group } \\
\hline I.A-B & 39 & 9.9 \\
\hline Good & 206 & 52.4 \\
\hline Intermediate & 51 & 13.0 \\
\hline Poor & 97 & 24.7 \\
\hline \multicolumn{3}{|l|}{ Treatment regimen } \\
\hline BEP & 275 & 70.0 \\
\hline EP & 56 & 14.2 \\
\hline Other regimen & 62 & 15.8 \\
\hline \multicolumn{3}{|l|}{ Follow-up status } \\
\hline Alive & 332 & 84.5 \\
\hline Exitus & 61 & 15.5 \\
\hline
\end{tabular}

NSGCT - nonseminomatous germ cell tumor. IGCCCG - International Germ Cell Cancer Collaborative Group, BEP - bleomycin, etoposide, cisplatin, EP - etoposide, cisplatin

\section{FN events}

During the study period, 71 patients (18.1\%) suffered FN events. There were 42 patients (32.8\%) without primary prophylaxis who suffered FN events. Out of these, 31 patients $(24.2 \%)$ suffered only one FN episode, and 11 patients (8.6\%) who suffered more than 1 episode. Out of 265 patients receiving prophylaxis, 29 patients (10.9\%) suffered FN events, 25 patients (9.4\%) suffered only one FN episode and 4 patients (1.5\%) suffered more than one episode. The data are summarized in Table 2. 
Table 2 FN episodes occurring in one patient

\begin{tabular}{|c|c|c|c|}
\hline Number of FN episodes & No prophylaxis & G-CSF prophylaxis & $\boldsymbol{P}$ \\
\hline 1 & $31 / 128(24.2 \%)$ & $25 / 265(9.4 \%)$ & 0.0002 \\
\hline 2 & $7 / 128(5.5 \%)$ & $3 / 265(1.1 \%)$ & 0.016 \\
\hline 3 & $1 / 128(0.8 \%)$ & $1 / 265(0.4 \%)$ & 0.5459 \\
\hline 4 & $3 / 128(2.3 \%)$ & $0 / 265(0.0 \%)$ & 0.034 \\
\hline any & $42 / 128(32.8 \%)$ & $29 / 265(10.9 \%)$ & 0.0000001 \\
\hline
\end{tabular}

FN - febrile neutropenia, G-CSF - granulocyte-colony stimulating factor

During the course of chemotherapy, 19 (4.8\%) patients died. Out of these, eight patients suffered FN events, four patients received primary G-CSF prophylaxis, while four patients did not receive primary GCSF prophylaxis. Patients on G-CSF prophylaxis had significantly longer time to FN compared to patients without prophylaxis ( $\mathrm{HR}=0.30,95 \% \mathrm{Cl} 0.18-0.50, P=0.00000001)$.

\section{Association between FN prophylaxis and patients/tumor characteristics}

The highest incidence of FN events (41.9\%) was observed in patients receiving chemotherapy regimen other than bleomycin, etoposide, cisplatin (BEP) or etoposide, cisplatin (EP). Two regimens most frequently associated with FN development were paclitaxel, bleomycin, etoposide, cisplatin (T-BEP) (66.7\%) and etoposide, iphosphamide, cisplatin (VIP) (50.0\%). Very high incidence of FN was also observed in patients with poor risk according to the IGCCCG classification (38.1\%) and in patients with extragonadal tumors (28.6\%).

There were $61 \mathrm{FN}$ events (20.4\%) in patients with NSGCTs and 10 events $(11.5 \%)$ occurred in patients with seminoma. While there was a significantly lower FN incidence in patients with NSGCT receiving prophylaxis when compared to patients without prophylaxis, the difference in incidences in patients with seminoma was not statistically significant $(11.9 \%$ vs $36.2 \% ; P<0.0001 ; 9.2 \%$ vs $18.2 \% ; P=0.26)$ (Figure 2).

We observed 59 FN events (16.8\%) in patients with gonadal tumors and 12 events were recorded (28.6\%) in patients with extragonadal tumors (Figure 3). For both primary tumor locations, there was a significantly lower incidence of FN events in patients receiving prophylaxis.

There were 22 (10.7\%) FN events in patients with good risk according to IGCCCG classification, 10 events (19.6\%) occurred in patients with intermediate risk and 37 events (38.1\%) were observed in patients with poor risk (Figure 4). There was a significantly lower incidence of FN events in patients receiving prophylaxis with good risk and poor risk. There was a trend to lower incidence in patients receiving G-CSF prophylaxis with intermediate risk. These data are summarized in Table 3.

FN events occurred in 40 patients (14.5\%) receiving BEP, 20 patients (66.7\%) receiving T-BEP, 5 patients (8.9\%) receiving EP, 4 patients (50.0\%) treated with VIP regimen and 2 patients $(22.2 \%)$ treated with paclitaxel, iphosphamide, cisplatin (TIP) regimen (Table 4). 
Table 3 FN events

\begin{tabular}{|l|c|c|c|c|c|c|c|}
\hline & \multicolumn{2}{|c|}{ Overall incidence } & \multicolumn{2}{l|}{ No prophylaxis } & \multicolumn{2}{c|}{ G-CSF prophylaxis } & $P$ \\
\hline & $\boldsymbol{N}$ & $\%$ & $\boldsymbol{N}$ & $\%$ & $\boldsymbol{N}$ & $\%$ & \\
\hline All FN events & $71 / 393$ & 18.1 & $42 / 128$ & 32.8 & $29 / 265$ & 10.9 & 0.0000001 \\
\hline Histology & & & & & & & \\
\hline Seminoma & $10 / 87$ & 11.5 & $4 / 22$ & 18.2 & $6 / 65$ & 9.2 & 0.2552 \\
\hline NSGCT & $61 / 299$ & 20.4 & $38 / 105$ & 36.2 & $23 / 194$ & 11.9 & 0.0000006 \\
\hline Primary tumor location & & & & & & & \\
\hline Gonadal & $59 / 351$ & 16.8 & $32 / 109$ & 29.4 & $27 / 242$ & 11.1 & 0.00002 \\
\hline Extragonadal & $12 / 42$ & 28.6 & $10 / 19$ & 52.6 & $2 / 23$ & 9.1 & 0.0017 \\
\hline IGCCCG risk group & & & & & & & \\
\hline Stage IA/B & $2 / 39$ & 5.1 & $0 / 12$ & 0.0 & $2 / 27$ & 7.4 & 0.3330 \\
\hline Good & $22 / 206$ & 10.7 & $12 / 55$ & 21.8 & $10 / 151$ & 6.6 & 0.0017 \\
\hline Intermediate & $10 / 51$ & 19.6 & $5 / 14$ & 35.7 & $5 / 37$ & 13.5 & 0.0747 \\
\hline Poor & $37 / 97$ & 38.1 & $25 / 47$ & 53.2 & $12 / 50$ & 24.0 & 0.0031 \\
\hline Chemotherapy regimen & & & & & & & \\
\hline BEP & $40 / 275$ & 14.5 & $16 / 71$ & 22.5 & $24 / 204$ & 11.8 & 0.0266 \\
\hline EP & $5 / 56$ & 8.9 & $3 / 23$ & 13.0 & $2 / 33$ & 6.1 & 0.3673 \\
\hline Other & $26 / 62$ & 41.9 & $23 / 34$ & 67.6 & $3 / 28$ & 10.7 & 0.000006 \\
\hline
\end{tabular}

FN - febrile neutropenia, G-CSF - granulocyte-colony stimulating factor, NSGCT - nonseminomatous germ cell tumor, IGCCCG - International Germ Cell Cancer Collaborative Group, BEP - bleomycin, etoposide, cisplatin, EP - etoposide, cisplatin

Table 4 FN events incidence based on chemotherapy regimen

\begin{tabular}{|c|c|c|c|}
\hline Regimen & FN & No prophylaxis & G-CSF prophylaxis \\
\hline BEP & $40 / 275(14.55 \%)$ & $16 / 71(22.54 \%)$ & $24 / 204(11.76 \%)$ \\
\hline EP & $5 / 56(8.93 \%)$ & $3 / 23(13.04 \%)$ & $2 / 33(6.06 \%)$ \\
\hline T-BEP & $20 / 30(66.67 \%)$ & $19 / 28(67.86 \%)$ & $1 / 2(50.00 \%)$ \\
\hline GETUG 13 & $0 / 11(0.00 \%)$ & $0 / 0(0.00 \%)$ & $0 / 11(0.00 \%)$ \\
\hline TIP & $2 / 9(22.22 \%)$ & $0 / 0(0.00 \%)$ & $2 / 9(22.22 \%)$ \\
\hline VIP & $4 / 8(50.00 \%)$ & $4 / 6(66.67 \%)$ & $0 / 2(0.00 \%)$ \\
\hline CDDP & $0 / 1(0.00 \%)$ & $0 / 0(0.00 \%)$ & $0 / 1(0.00 \%)$ \\
\hline etoposide + CBDCA & $0 / 1(0.00 \%)$ & $0 / 0(0.00 \%)$ & $0 / 1(0.00 \%)$ \\
\hline BEP/CBDCA & $0 / 1(0.00 \%)$ & $0 / 0(0.00 \%)$ & $0 / 1(0.00 \%)$ \\
\hline CHOP, EP & $0 / 1(0.00 \%)$ & $0 / 0(0.00 \%)$ & $0 / 1(0.00 \%)$ \\
\hline
\end{tabular}

FN - febrile neutropenia, G-CSF - granulocyte-colony stimulating factor, BEP - bleomycin, etoposide, cisplatin, EP - etoposide, cisplatin, T-BEP - paclitaxel, bleomycin, etoposide, cisplatin, GETUG 13 - dose dense regimen [32], TIP - paclitaxel, iphosphamide, cisplatin, VIP - etoposide, iphosphamide, cisplatin, CDDP - cisplatin, CBDCA - carboplatin, BEP/CBDCA - bleomycin, etoposide, carboplatin, CHOP - cyclophosphamide, doxorubicin, vincristine, prednisone

\section{Association between overall survival and G-CSF prophylaxis}

Median follow-up of all patients was 66 months (0-224 months). Median follow-up of alive patients was 82 months (6 - 224 months). There were 61 deaths (15.5\%) in our study population (Table 5). 2- and 5year OS of the study group was $86.8 \%$ and $83.1 \%$, respectively. 
Table 5 Cause of death

\begin{tabular}{|l|c|c|c|}
\hline \multicolumn{1}{|c|}{ Cause of death } & $\boldsymbol{N}$ & No prophylaxis & G-CSF Prophylaxis \\
\hline Treatment related death & $19(4.8 \%)$ & $13(10.2 \%)$ & $6(2.3 \%)$ \\
\hline Disease progression & $39(9.9 \%)$ & $19(14.8 \%)$ & $20(7.5 \%)$ \\
\hline Unknown & $1(0.3 \%)$ & $0(0.0 \%)$ & $1(0.4 \%)$ \\
\hline Second primary malignancy & $1(0.3 \%)$ & $0(0.0 \%)$ & $1(0.4 \%)$ \\
\hline Cancer unrelated death & $1(0.3 \%)$ & $1(0.8 \%)$ & $0(0.0 \%)$ \\
\hline
\end{tabular}

G-CSF - granulocyte-colony stimulating factor

Patients receiving G-CSF prophylaxis had significantly longer OS when compared to patients without prophylaxis ( $\mathrm{HR}=0.44,95 \% \mathrm{Cl} 0.26-0.75 ; P=0.0009)$ (Figure 5). The results are summarized in Table 6. Patients with gonadal GCT and patients with NSGCT histology receiving G-CSF prophylaxis had significantly longer survival compared to patients without prophylaxis. $(\mathrm{HR}=0.43,95 \% \mathrm{Cl} 0.23-0.81 ; P=$ $0.0032, \mathrm{HR}=0.43,95 \% \mathrm{Cl} 0.25-0.75 ; P=0.0012$ respectively) (Figure 6). Patients receiving G-CSF prophylaxis with EP chemotherapy regimen had significantly longer OS when compared to patients without prophylaxis. $(\mathrm{HR}=0.11,95 \% \mathrm{Cl} 0.02-0.50 ; P=0.0119)$. We have also observed a trend to longer OS in patients receiving G-CSF prophylaxis with BEP chemotherapy regimen when compared to patients without prophylaxis $(\mathrm{HR}=0.52,95 \% \mathrm{Cl} 0.23-1.18 ; P=0.0762)$. We have also observed longer OS in good risk patients receiving prophylaxis ( $\mathrm{HR}=0.28,95 \% \mathrm{Cl} 0.04-1.92 ; P=0.1390)$.

Table 6 Overall survival

\begin{tabular}{|c|c|c|c|c|c|c|}
\hline & G-CSF prophylaxis & $N$ & HR & lower $95 \% \mathrm{CI}$ & upper 95\% CI & $P$ \\
\hline All patients & $1 / 0$ & $128 / 265$ & 0.44 & 0.26 & 0.75 & 0.0009 \\
\hline \multicolumn{7}{|c|}{ IGCCCG risk group } \\
\hline Stage IA/B & $1 / 0$ & $27 / 12$ & 0 & 0 & 0 & 0 \\
\hline Good & $1 / 0$ & $151 / 55$ & 0.28 & 0.04 & 1.92 & 0.1390 \\
\hline Intermediate & $1 / 0$ & $37 / 14$ & 0.85 & 0.07 & 10.11 & 0.8968 \\
\hline Poor & $1 / 0$ & $50 / 47$ & 0.70 & 0.40 & 1.21 & 0.1986 \\
\hline \multicolumn{7}{|c|}{ Chemotherapy regimen } \\
\hline BEP & $1 / 0$ & $204 / 71$ & 0.52 & 0.23 & 1.19 & 0.0762 \\
\hline EP & $1 / 0$ & $33 / 23$ & 0.11 & 0.02 & 0.50 & 0.0119 \\
\hline Other & $1 / 0$ & $28 / 34$ & 1.03 & 0.47 & 2.27 & 0.9454 \\
\hline \multicolumn{7}{|l|}{ Tumor histology } \\
\hline Seminoma & $1 / 0$ & $65 / 22$ & 0 & 0 & 0 & 0 \\
\hline NSGCT & $1 / 0$ & $194 / 105$ & 0.43 & 0.25 & 0.75 & 0.0012 \\
\hline \multicolumn{7}{|c|}{ Primary tumor location } \\
\hline Gonadal & $1 / 0$ & $242 / 109$ & 0.43 & 0.23 & 0.81 & 0.0032 \\
\hline Extragonadal & $1 / 0$ & $23 / 19$ & 0.62 & 0.21 & 1.76 & 0.3570 \\
\hline
\end{tabular}

G-CSF - granulocyte-colony stimulating factor, IGCCCG - International Germ Cell Cancer Collaborative Group, BEP - bleomycin, etoposide, cisplatin, EP - etoposide, cisplatin, NSGCT - nonseminomatous germ cell tumor

\section{Discussion}


Febrile neutropenia complicates the course of chemotherapy, contributing to prolonged hospital stays, often resulting in increased morbidity and mortality. $[18,19]$ Patients receiving primary G-CSF prophylaxis had significantly lower incidence of FN compared to patients without primary G-CSF prophylaxis. We have also observed a trend to lower $\mathrm{FN}$ incidence in patients receiving pegfilgrastim when compared to FN incidence in patients receiving filgrastim. We suppose, that this could be affected by worse compliance to filgrastim compared to pegfilgrastim. In hospitalized patients with poor performance status, we preferred filgrastim due to lower cost. Poor performance status has been identified previously as a significant FN risk factor.[12] We observed highest incidence of FN in first cycle of chemotherapy, similarly as shown previously.[12,20] This could be related to the use of G-CSF in subsequent cycles if the patient developed neutropenia in the first cycle, and/or dose reductions in patients with previous FN. Hematologic toxicity is also more pronounced in patients with lower baseline neutrophil and lymphocyte counts possibly related to tumor-induced immunosuppression.

We observed FN incidence of $32.8 \%$ overall in patients without G-CSF prophylaxis, which is higher compared to most reports. [11, 12, 21] However, Nishikawa et al observed even higher incidence (39.5\%). [9] In our study, FN incidence was especially high in patients treated with T-BEP and VIP. One factor contributing to the discrepancy may be the difference in study populations. Terbuch et al measured only $17 \% \mathrm{FN}$ incidence.[12] In their study population, poor risk patients comprised only $12 \%$ of all metastatic patients opposite to $24.7 \%$ in our study. We have observed that FN incidence positively correlates with TNM stage and IGCCCG risk group. While patients in good risk class had 21.8\% FN incidence, there was $53.2 \% \mathrm{FN}$ incidence in poor risk patients without primary G-CSF prophylaxis. This is in line with previous findings that poor risk disease is a risk factor for febrile neutropenia. Therefore, study population structure needs to be taken into account when comparing FN incidence rates. However, even patients with good risk disease had higher FN incidence (21.8\%) in our cohort when compared to literature data.[12, 22] Culine et al observed 7\% FN incidence in patients with good risk NSGCTs receiving BEP chemotherapy regimen and 5\% FN incidence in patients receiving EP regimen, while Terbuch et al found $17.7 \%$ incidence in patients with good risk disease.[12, 22]

Primary G-CSF prophylaxis decreased FN incidence in patients with NSGCTs and seminomas, however, this difference in seminoma subgroup didn't reached statistical significance. We suppose that this observation could be due to sample size, as seminomas represented only $22.1 \%$ of study population, as well as due to lower risk of $\mathrm{FN}$ in seminomas without prophylaxis.

FN incidence is affected by chemotherapy regimen as shown in previous studies.[23-25] Patients treated with T-BEP or VIP have significantly higher rates of hematologic toxicity when compared to patients treated with BEP regimen.[24, 26, 27] This could explain higher incidence of FN in extragonadal GCTs as extragonadal GCTs were more frequently treated with VIP or T-BEP regimens compared to patients with gonadal tumors. While $15.8 \%$ of patients with extragonadal GCT were treated with VIP chemotherapy regimen, only $2.8 \%$ of patients with gonadal tumors received VIP regimen. T-BEP chemotherapy was also used more frequently in patients with extragonadal GCTs ( $26.3 \%$ vs $21.1 \%)$. Secondly, higher proportion 
of patients with extragonadal GCTs had poor risk disease when compared to patients with gonadal GCTs $(45.2 \%$ vs $21.4 \%)$.

Our data suggest that G-CSF prophylaxis decrease FN incidence in all subgroups except for patients with stage I disease. According to clinical practice guidelines for the management of FN issued in 2010, individualized approach should be used, if the expected FN incidence falls between 10 and 20\%.[25] In our study, there were two subgroups of patients that fell into this category, patients with seminoma and patients receiving EP chemotherapy. Even though we observed a numerically lower FN incidence in patients receiving primary G-CSF prophylaxis when compared to patients without prophylaxis, this difference was not statistically significant.

We observed a statistically significant benefit in OS in patients receiving primary G-CSF prophylaxis. While this effect was consistent for all study subgroups, most pronounced was in patients treated with EP regimen, in non-seminomas and in gonadal primary. Analysis of causes of death showed, that primary G-CSF decreased not only treatment related deaths but was associated with lower risk of disease progression as well. This could be related more frequent chemotherapy dose modification and treatment delays due to neutropenia in patients without primary prophylaxis, but we suppose, that other immune related mechanism could be related to this observation as well. Previously, it was shown that immune related factors including PD-L1 expression, systemic inflammatory index and serum cytokines are associated with TGCTs prognosis.[28-30] We suppose, that administration of G-CSF could have pleiotropic effect on immune system beyond neutrophil count and therefore, better survival of patients that received G-CSF prophylaxis could be related to this mechanism as well.[31]

To our knowledge, this is the largest study assessing the effect of primary G-CSF prophylaxis in GCT patients that reflects routine clinical practice in tertiary cancer center. This study is limited by its retrospective, non-randomized and single-center design. Most patients received BEP or EP chemotherapy. Number of patients receiving other chemotherapy regimens is small and not proportionately distributed in subgroups, therefore our results mostly apply to GCT patients treated with BEP or EP regimens. The number of patients in several subgroups was limited. Lastly, some patients who did not receive primary G-CSF prophylaxis received G-CSF prophylaxis in subsequent cycles secondary to the occurrence of neutropenia or FN in the previous cycle.

\section{Conclusion}

In conclusion in this large, retrospective study we confirmed prophylactic effect of G-CSF on incidence of FN in GCTs patients treated with first line of chemotherapy for metastatic disease. In our study, we showed for the first time that patients receiving G-CSF prophylaxis had significantly longer OS compared to patients without prophylaxis and that this effect is not due only to prevention of treatment related deaths but due to decreased risk of disease progression as well. Prospective validation of this observation is warranted. Based on our data, we suggest, that G-CSF prophylaxis should be considered in 
daily clinical practice in metastatic GCTs patients treated with first line chemotherapy especially in patients with high risk features.

\section{List Of Abbreviations}

\begin{tabular}{ll} 
FN & - Febrile neutropenia \\
\hline G-CSF & - Granulocyte-colony stimulating factor \\
\hline GCTs & - Testicular germ cell tumors \\
\hline IGCCCG & - International Germ Cell Cancer Collaboration Group \\
\hline NCI & - National Cancer Institute \\
\hline NSGCT & - Non-seminomatous germ cell tumor \\
\hline OS & - Overall survival \\
\hline T-BEP & - Paclitaxel, bleomycin, etoposide, cisplatin \\
\hline TIP & - Paclitaxel, iphosphamide, cisplatin \\
\hline VIP & - Etoposide, iphosphamide, cisplatin
\end{tabular}

\section{Declarations}

\section{Ethics approval}

The Institutional Review Board of the National Cancer Institute, Bratislava, Slovakia approved this study and granted a waiver of consent form for the collection, analysis and publication of the retrospectively obtained and anonymised data for this non-interventional study.

\section{Consent for publication}

Not applicable.

\section{Availability of data and materials}

The dataset supporting the conclusions of this article is included within the article.

\section{Competing interests}

None declared.

\section{Funding}

This research was funded by the Slovak Research and Development Agency (APVV), grant number APVV15-0086, by Ministry of Health 2018/39-LFUK-13 and by Scientific Grant Agency (VEGA) contracts No. 


\section{Authors' contributions}

Conceptualization, JM and MM; Data curation, NH, MCH, KR, KK, JO, PP, VD, DS, ZS, JM, MM; Formal analysis, $\mathrm{NH}, \mathrm{MM}$; Investigation, NH, MCH, KR, KK, JO, PP, VD, DS, ZS, JM, MM; Methodology, NH, JM, MM; Visualization, $\mathrm{NH}$ and $\mathrm{MM}$; Writing - original draft, $\mathrm{NH}$; Writing - review \& editing, $\mathrm{NH}, \mathrm{MCH}, \mathrm{KR}, \mathrm{KK}, \mathrm{JO}$, $P P, V D, D S, Z S, J M, M M$

\section{Acknowledgements}

We would like to acknowledge Veronika Remenarova for her excellent technical help. We are grateful to all patients for their participation in the study.

\section{References}

1. Nigam M, Aschebrook-Kilfoy B, Shikanov S, Eggener S: Increasing incidence of testicular cancer in the United States and Europe between 1992 and 2009. World J Urol 2015, 33(5):623-631.

2. Laguna M, Albers P, Algaba F, Bokemeyer C, Boormans J, Fischer S, Fizazi K, Gremmels H, Leão R, Nicol D: EAU Guidelines. In: EAU Annual Congress Amsterdam 2020: EAU Guidelines Office; 2019.

3. Einhorn LH: Treatment of testicular cancer: a new and improved model. J Clin Oncol 1990, 8(11):1777-1781.

4. Beyer J, Albers P, Altena R, Aparicio J, Bokemeyer C, Busch J, Cathomas R, Cavallin-Stahl E, Clarke NW, Claßen $J$ et al: Maintaining success, reducing treatment burden, focusing on survivorship: highlights from the third European consensus conference on diagnosis and treatment of germ-cell cancer. Ann Oncol 2013, 24(4):878-888.

5. Travis LB, Beard C, Allan JM, Dahl AA, Feldman DR, Oldenburg J, Daugaard G, Kelly JL, Dolan ME, Hannigan R et al: Testicular cancer survivorship: research strategies and recommendations. J Natl Cancer Inst 2010, 102(15):1114-1130.

6. Chovanec M, Vasilkova L, Setteyova L, Obertova J, Palacka P, Rejlekova K, Sycova-Mila Z, Kalavska $\mathrm{K}$, Svetlovska D, Cingelova S et al: Long-Term Cognitive Functioning in Testicular Germ-Cell Tumor Survivors. Oncologist 2018, 23(5):617-623.

7. Oun R, Moussa YE, Wheate NJ: The side effects of platinum-based chemotherapy drugs: a review for chemists. Dalton Transactions 2018, 47(19):6645-6653.

8. Crawford J, Becker PS, Armitage JO, Blayney DW, Chavez J, Curtin P, Dinner S, Fynan T, Gojo I, Griffiths EA et al: Myeloid Growth Factors, Version 2.2017, NCCN Clinical Practice Guidelines in Oncology. 2017, 15(12):1520.

9. Nishikawa M, Miyake H, Fujisawa M: Identification of risk factors predicting febrile neutropenia in patients with metastatic germ cell tumors receiving cisplatin-based combination chemotherapy. Int $J$ 
Urol 2017, 24(6):449-453.

10. Cullen M, Baijal S: Prevention of febrile neutropenia: use of prophylactic antibiotics. $\mathrm{Br} J$ Cancer 2009, 101 Suppl 1(Suppl 1):S11-14.

11. Counsell R, Pratt J, Williams MV: Chemotherapy for germ cell tumours: prophylactic ciprofloxacin reduces the incidence of neutropenic fever. Clin Oncol (R Coll Radiol) 1994, 6(4):232-236.

12. Terbuch A, Posch F, Partl R, Zurl B, Bauernhofer T, Pichler M, Szkandera J, Hutterer GC, Pummer K, Kapp KS et al: Risk stratification for febrile neutropenia in patients with testicular germ cell tumors. Cancer Med 2018, 7(2):508-514.

13. Feldman DR, Voss MH, Jacobsen EP, Jia X, Suarez JA, Turkula S, Sheinfeld J, Bosl GJ, Motzer RJ, Patil S: Clinical features, presentation, and tolerance of platinum-based chemotherapy in germ cell tumor patients 50 years of age and older. Cancer 2013, 119(14):2574-2581.

14. Wang $\mathrm{L}$, Baser $\mathrm{O}$, Kutikova $\mathrm{L}$, Page $\mathrm{JH}$, Barron $\mathrm{R}$ : The impact of primary prophylaxis with granulocyte colony-stimulating factors on febrile neutropenia during chemotherapy: a systematic review and meta-analysis of randomized controlled trials. Support Care Cancer 2015, 23(11):3131-3140.

15. Fossa SD, Kaye SB, Mead GM, Cullen M, de Wit R, Bodrogi I, van Groeningen CJ, De Mulder PH, Stenning S, Lallemand E et al: Filgrastim during combination chemotherapy of patients with poorprognosis metastatic germ cell malignancy. European Organization for Research and Treatment of Cancer, Genito-Urinary Group, and the Medical Research Council Testicular Cancer Working Party, Cambridge, United Kingdom. J Clin Oncol 1998, 16(2):716-724.

16. de Naurois J, Novitzky-Basso I, Gill MJ, Marti FM, Cullen MH, Roila F, Group ObotEGW: Management of febrile neutropenia: ESMO Clinical Practice Guidelines. Annals of Oncology 2010, 21(suppl_5):v252-v256.

17. NCSS 2019 Statistical Software. In. Kaysville, Utah, USA: NCSS, LLC; 2019.

18. Kuderer NM, Dale DC, Crawford J, Cosler LE, Lyman GH: Mortality, morbidity, and cost associated with febrile neutropenia in adult cancer patients. Cancer 2006, 106(10):2258-2266.

19. Caggiano V, Weiss RV, Rickert TS, Linde-Zwirble WT: Incidence, cost, and mortality of neutropenia hospitalization associated with chemotherapy. Cancer 2005, 103(9):1916-1924.

20. Crawford J, Dale DC, Kuderer NM, Culakova E, Poniewierski MS, Wolff D, Lyman GH: Risk and Timing of Neutropenic Events in Adult Cancer Patients Receiving Chemotherapy: The Results of a Prospective Nationwide Study of Oncology Practice. 2008, 6(2):109.

21. Aagaard T, Roen A, Reekie J, Daugaard G, Brown PdN, Specht L, Sengeløv H, Mocroft A, Lundgren J, Helleberg M: Development and Validation of a Risk Score for Febrile Neutropenia After Chemotherapy in Patients With Cancer: The FENCE Score. JNCI Cancer Spectrum 2018, 2(4).

22. Culine S, Kerbrat P, Kramar A, Theodore C, Chevreau C, Geoffrois L, Bui NB, Peny J, Caty A, Delva R et al: Refining the optimal chemotherapy regimen for good-risk metastatic nonseminomatous germ-cell tumors: a randomized trial of the Genito-Urinary Group of the French Federation of Cancer Centers (GETUG T93BP). Ann Oncol 2007, 18(5):917-924. 
23. Nichols CR, Catalano PJ, Crawford ED, Vogelzang NJ, Einhorn LH, Loehrer PJ: Randomized comparison of cisplatin and etoposide and either bleomycin or ifosfamide in treatment of advanced disseminated germ cell tumors: an Eastern Cooperative Oncology Group, Southwest Oncology Group, and Cancer and Leukemia Group B Study. J Clin Oncol 1998, 16(4):1287-1293.

24. Mardiak J, Sálek T, Sycová-Milá Z, Obertová J, Recková M, Mego M, Hlavatá Z, Brozmanová K, Risnyovzská Z, Svetlovská D et al: Paclitaxel, bleomycin, etoposide, and cisplatin (T-BEP) as initial treatment in patients with poor-prognosis germ cell tumors (GCT): a phase II study. Neoplasma 2007, 54(3):240-245.

25. Aapro MS, Bohlius J, Cameron DA, Dal Lago L, Donnelly JP, Kearney N, Lyman GH, Pettengell R, TjanHeijnen VC, Walewski J et al: 2010 update of EORTC guidelines for the use of granulocyte-colony stimulating factor to reduce the incidence of chemotherapy-induced febrile neutropenia in adult patients with lymphoproliferative disorders and solid tumours. Eur J Cancer 2011, 47(1):8-32.

26. de Wit R, Stoter G, Sleijfer D, Neijt JP, ten Bokkel Huinink WW, de Prijck L, Collette L, Sylvester R: Four cycles of BEP vs four cycles of VIP in patients with intermediate-prognosis metastatic testicular nonseminoma: a randomized study of the EORTC Genitourinary Tract Cancer Cooperative Group. British Journal of Cancer 1998, 78(6):828-832.

27. Wit R, Skoneczna I, Daugaard G, Santis M, Garin A, Aass N, Witjes A, Albers P, White J, Germà-Lluch J et al: Randomized Phase III Study Comparing Paclitaxel-Bleomycin, Etoposide, and Cisplatin (BEP) to Standard BEP in Intermediate-Prognosis Germ-Cell Cancer: Intergroup Study EORTC 30983. Journal of clinical oncology : official journal of the American Society of Clinical Oncology 2012, 30:792-799.

28. Cierna Z, Mego M, Miskovska V, Machalekova K, Chovanec M, Svetlovska D, Hainova K, Rejlekova K, Macak D, Spanik S et al: Prognostic value of programmed-death-1 receptor (PD-1) and its ligand 1 (PD-L1) in testicular germ cell tumors. Ann Oncol 2016, 27(2):300-305.

29. Chovanec M, Cierna Z, Miskovska V, Machalekova K, Kalavska K, Rejlekova K, Svetlovska D, Macak D, Spanik S, Kajo $\mathrm{K}$ et al: Systemic immune-inflammation index in germ-cell tumours. British journal of cancer 2018, 118(6):831-838.

30. Svetlovska D, Miskovska V, Cholujova D, Gronesova P, Cingelova S, Chovanec M, Sycova-Mila Z, Obertova J, Palacka P, Rajec J et al: Plasma Cytokines Correlated With Disease Characteristics, Progression-Free Survival, and Overall Survival in Testicular Germ-Cell Tumor Patients. Clin Genitourin Cancer 2017, 15(3):411-416.e412.

31. Xiao B-G, Lu C-Z, Link H: Cell biology and clinical promise of G-CSF: immunomodulation and neuroprotection. J Cell Mol Med 2007, 11(6):1272-1290.

\section{Figures}




\section{Proportion of patients with febrile neutropenia}

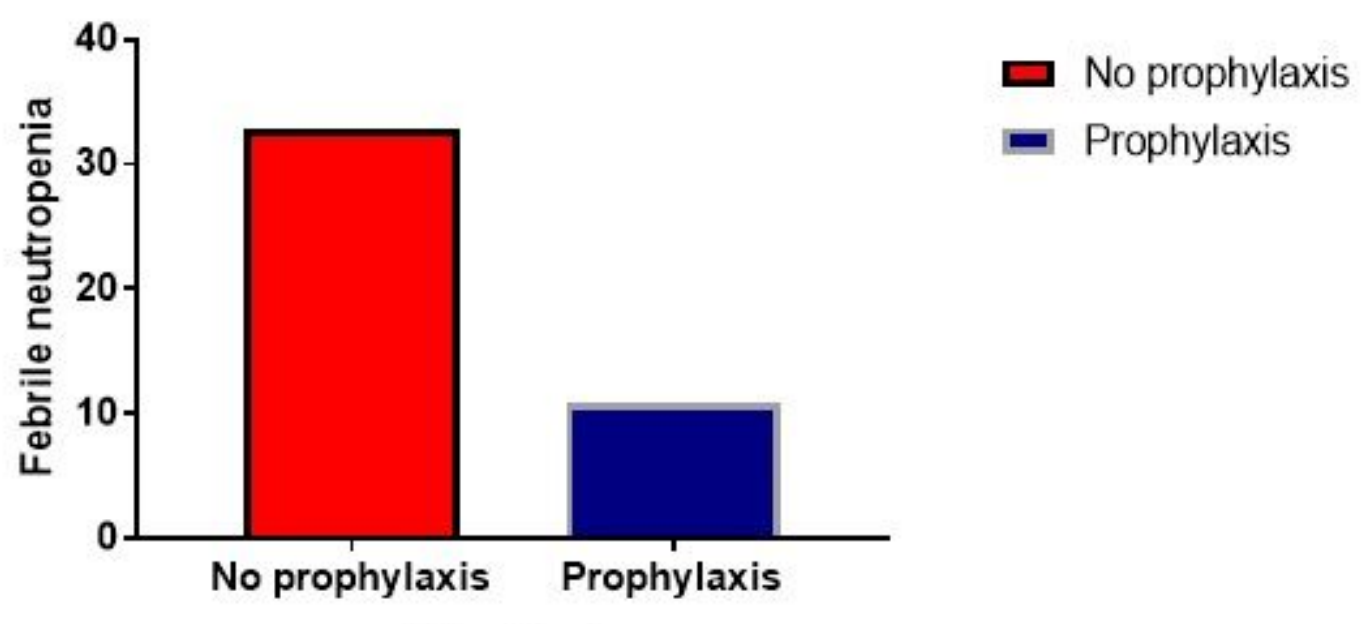

All patients

Figure 1

Incidence of febrile neutropenia in all germ cell tumor patients with and without primary granulocytecolony stimulating factor prophylaxis 


\section{Proportion of patients with febrile neutropenia}

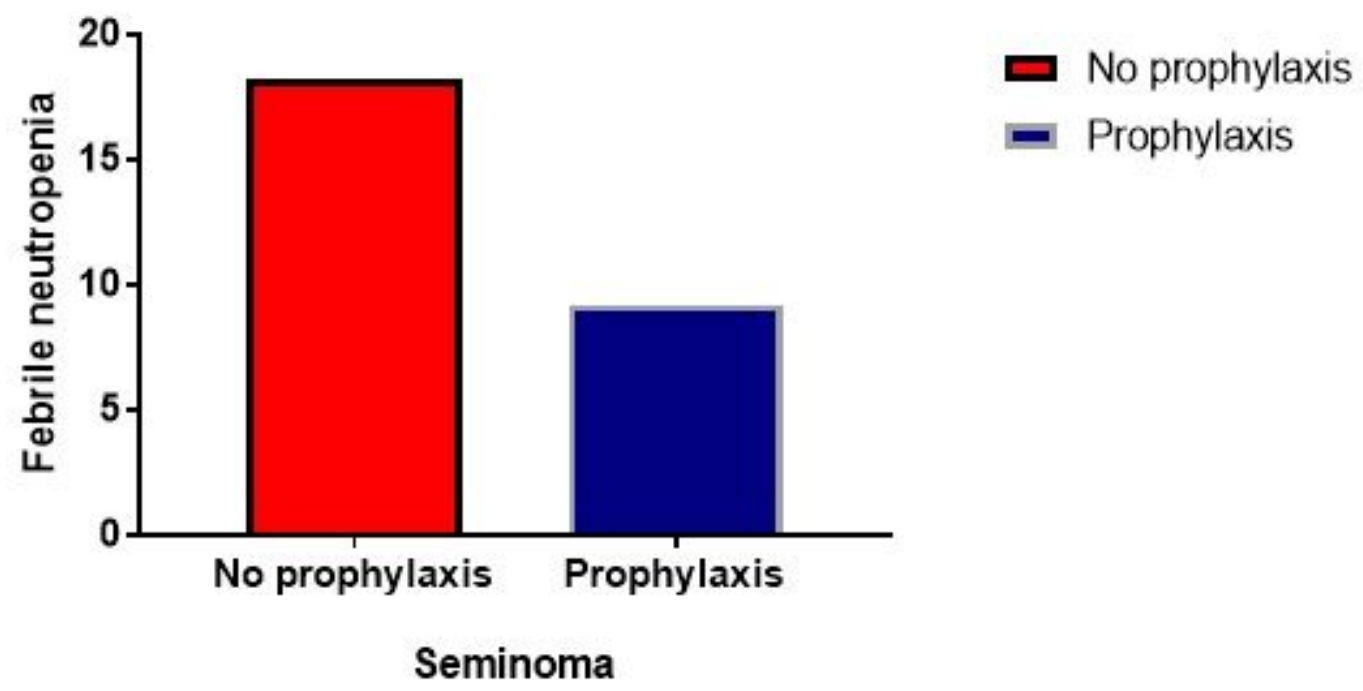

\section{Proportion of patients with febrile neutropenia}

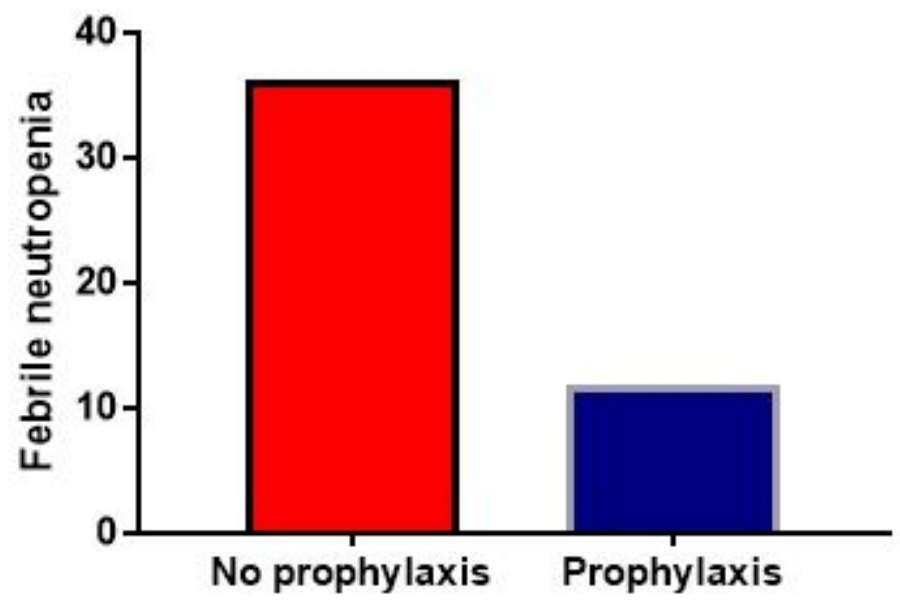

두 prophylaxis

- Prophylaxis

Non-seminoma

Figure 2

A. Incidence of febrile neutropenia in seminoma patients with and without primary granulocyte-colony stimulating factor prophylaxis. B. Incidence of febrile neutropenia in patients with NSGCT histology with and without primary granulocyte-colony stimulating factor prophylaxis. 


\section{Proportion of patients with febrile neutropenia}

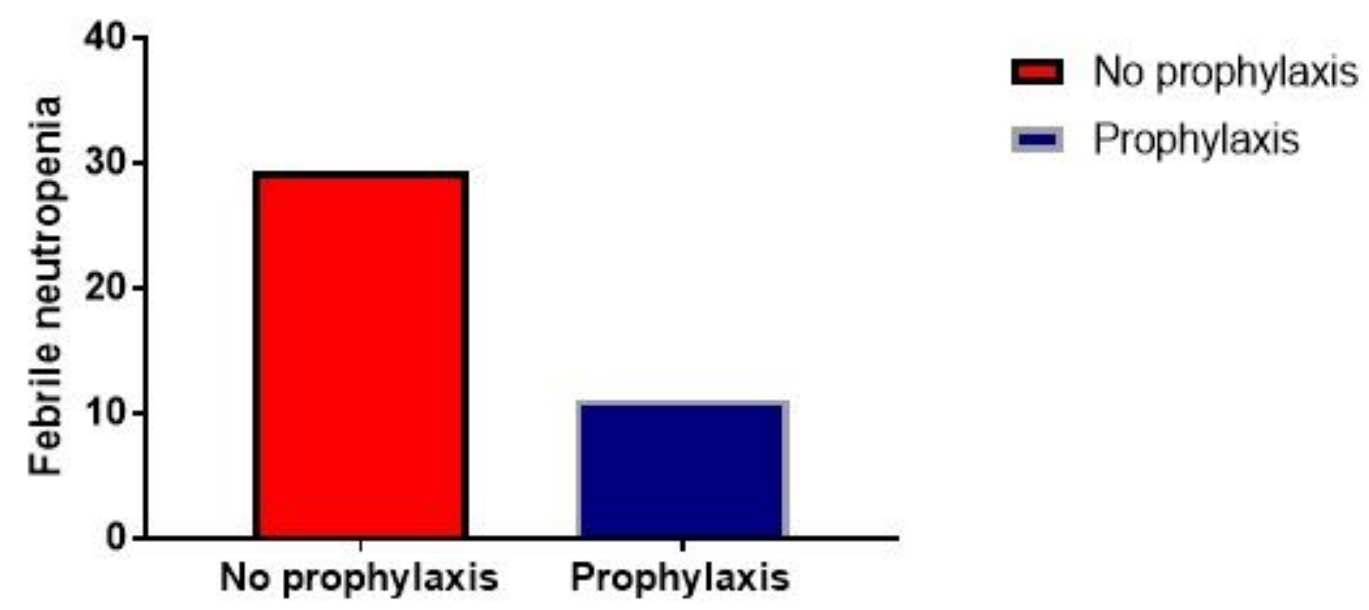

Gonadal

Proportion of patients with febrile neutropenia

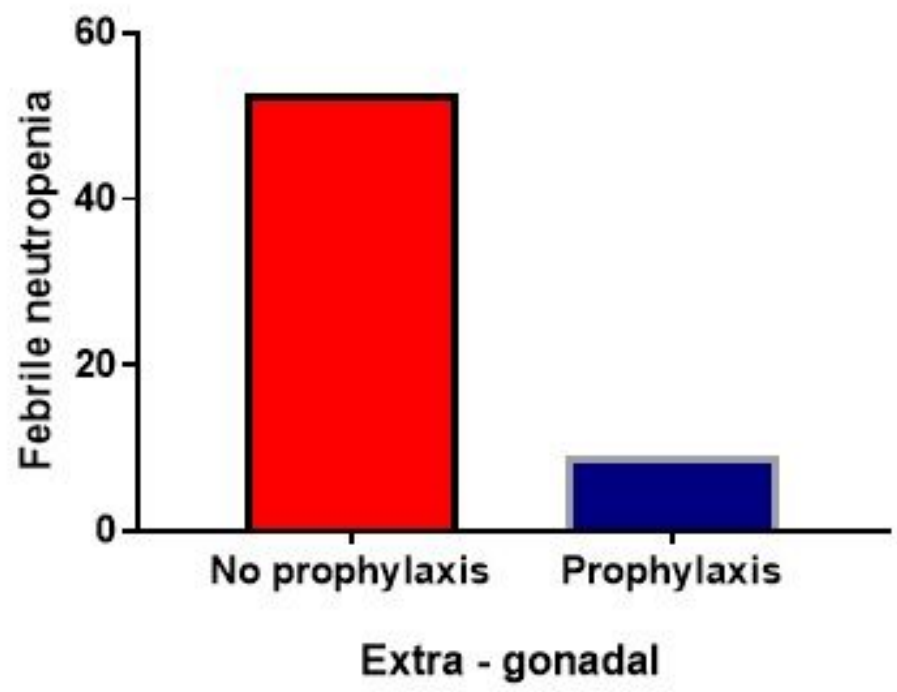

$\square$ No prophylaxis

- Prophylaxis

Figure 3

A. Incidence of febrile neutropenia in patients with gonadal primary GCTs with and without primary granulocyte-colony stimulating factor prophylaxis. B. Incidence of febrile neutropenia in patients with extragonadal primary GCTs with and without primary granulocyte-colony stimulating factor prophylaxis 
(A) Proportion of patients with febrile neutropenia

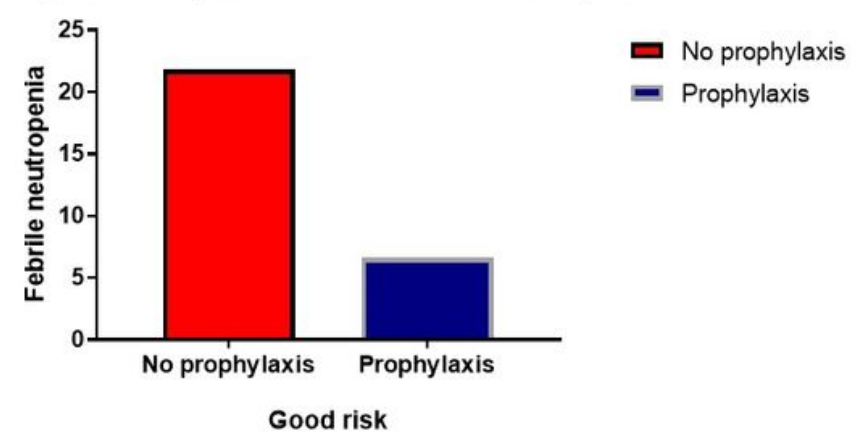

(B) Proportion of patients with febrile neutropenia

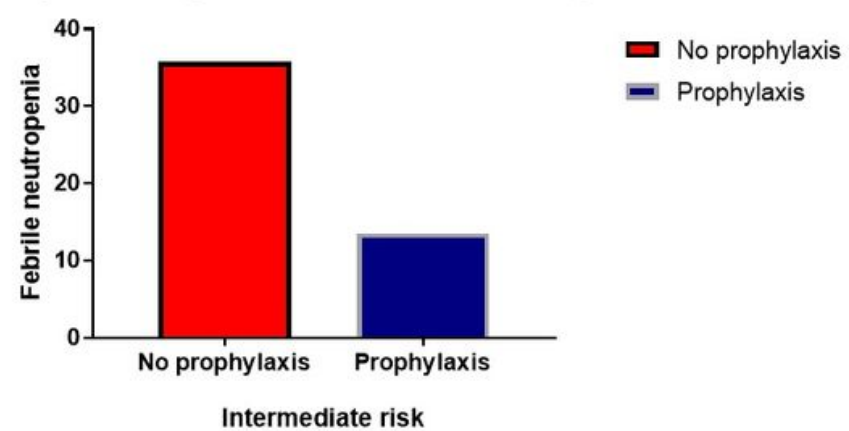

(C) Proportion of patients with febrile neutropenia

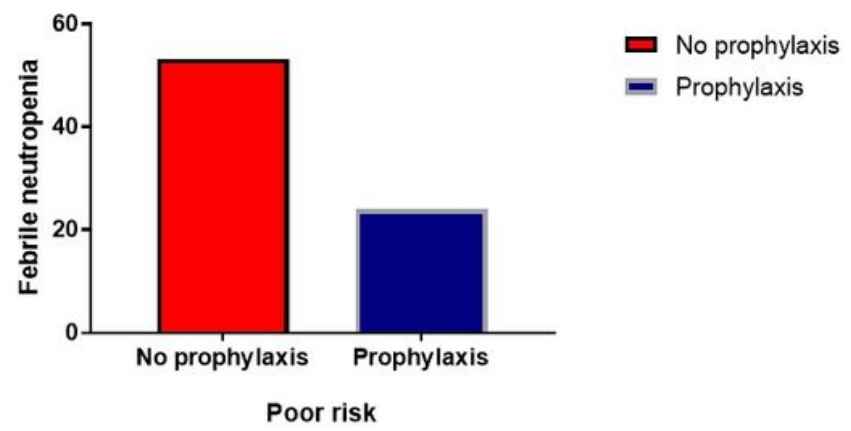

\section{Figure 4}

Incidence of febrile neutropenia in GCT patients according to IGCCCG risk group with and without primary granulocyte-colony stimulating factor prophylaxis: (A) good risk, (B) intermediate risk, (C) poor risk.

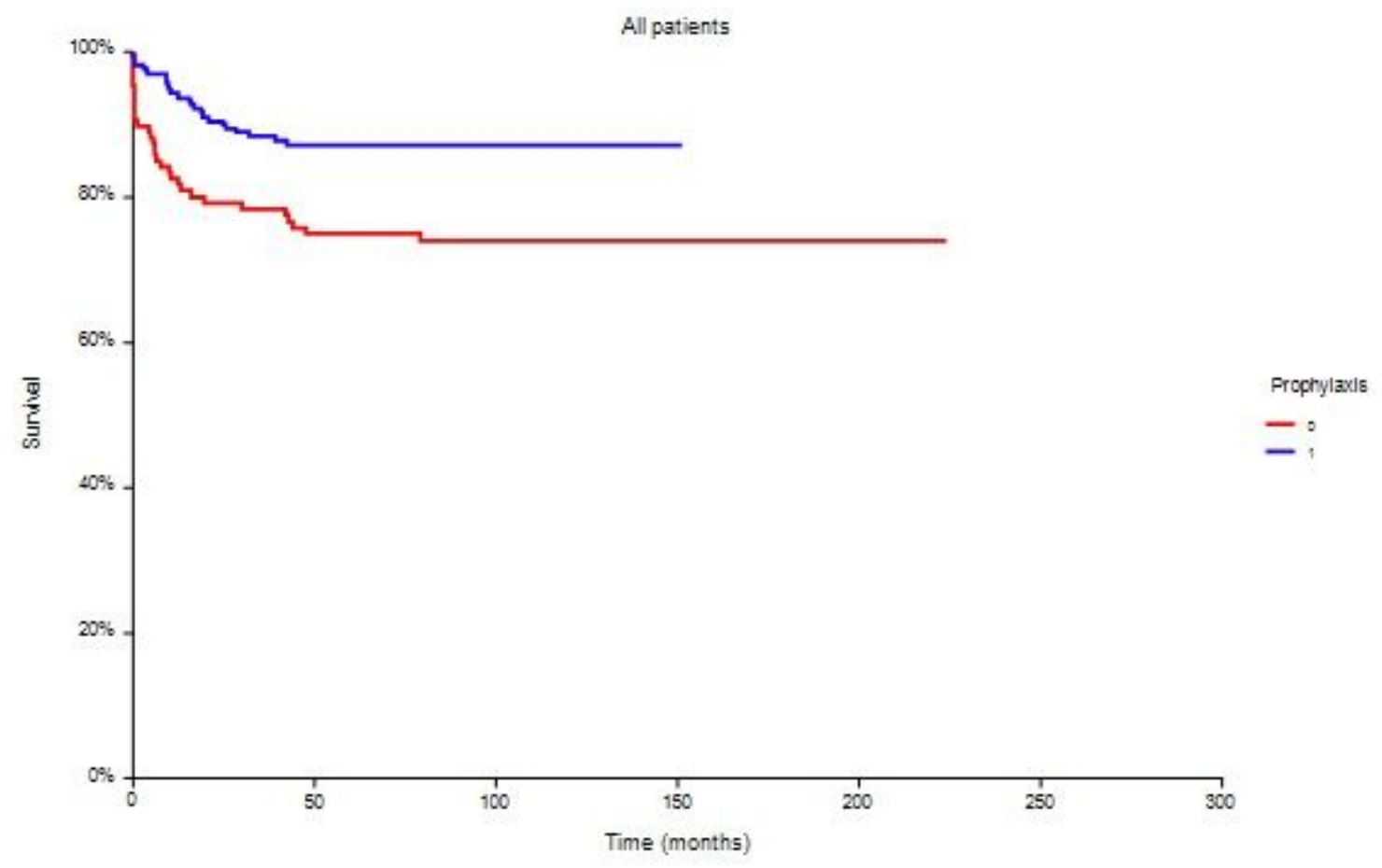

Figure 5 
Kaplan-Meier estimates of probabilities of overall survival according to primary G-CSF prophylaxis in testicular germ cell tumor patients $(N=393)$, Hazard ratio $=0.44,95 \%$ confidence interval $0.26-0.75, P=$ 0.0009, 0-no primary G-CSF prophylaxis; 1-primary G-CSF prophylaxis with filgrastim/pegfilgrastim.
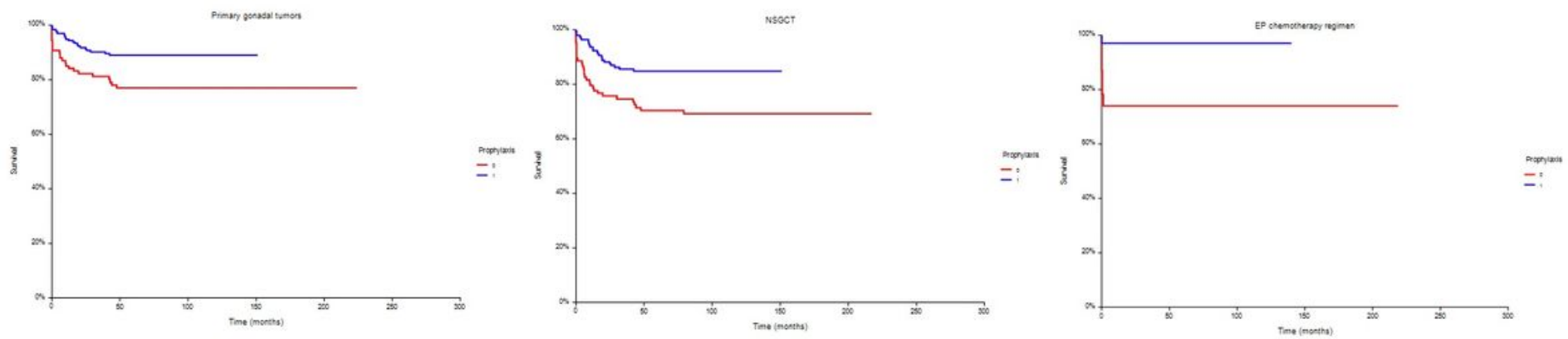

\section{Figure 6}

A Kaplan-Meier estimates of probabilities of overall survival according to primary G-CSF prophylaxis in patients with primary gonadal germ cell tumors $(N=351)$, Hazard ratio $=0.43,95 \%$ confidence interval 0.23-0.81, $\mathrm{P}=0.0032,0$-no primary G-CSF prophylaxis; 1 -primary G-CSF prophylaxis with filgrastim/pegfilgrastim. B Kaplan-Meier estimates of probabilities of overall survival according to primary G-CSF prophylaxis in patients with nonseminomatous germ cell tumors $(\mathrm{N}=299)$, Hazard ratio = $0.43,95 \%$ confidence interval $0.25-0.75, P=0.0012,0-$ no primary G-CSF prophylaxis; 1 -primary G-CSF prophylaxis with filgrastim/pegfilgrastim. C Kaplan-Meier estimates of probabilities of overall survival according to primary G-CSF prophylaxis in patients treated with etoposide and cisplatin $(\mathrm{N}=56), \mathrm{Hazard}$ ratio $=0.11,95 \%$ confidence interval $0.02-0.50, \mathrm{P}=0.0119,0-$ no primary G-CSF prophylaxis; 1 -primary G-CSF prophylaxis with filgrastim/pegfilgrastim.

\section{Supplementary Files}

This is a list of supplementary files associated with this preprint. Click to download.

- FlowChart.pdf 